\title{
Users' movement and the challenge to psychiatrists
}

\author{
Mark Cohen
}

In recent years the psychiatric users' movement has become more prominent and powertul. In this article aspects of the movement and some of the resultant challenges to psychiatrists are described. Psychiatrists are often regarded by users as resistant to its development. The author argues that psychiatrists may benefit from a creative engagement with this process of change.

In recent years there has been an increasingly active users' movement in relation to psychiatric services (i.e. the formation of groups who express opinions regarding their experience as psychiatric patients). This has been described as being in keeping with other "new social movements" such as the gay rights movement (Rogers \& Pilgrim, 1991) but has also been congruent with political changes (Department of Health. 1991) and associated management and organisational developments within the National Health Service (NHS) (including the purchaser-provider split). These latter changes have encouraged the development of user involvement in all aspects of the decision-making process (e.g. the planning and delivery of service) and a cultural change towards a "thinking, questioning, sceptical . . . people" (Wedderburn-Tate, 1994).

Despite the increasing importance of this development, perhaps particularly for psychiatry which has always been subject to public criticism, there seems to have been little written about the potential implications for the profession. There is evidence, however, that psychiatrists can be active in promoting user involvement (Summers \& Kehoe, 1996).

In this article I describe the roots, practice and the common demands made by the psychiatric user movement. Finally, I suggest some of the challenges to psychiatry which arise from this development.

\section{Roots of the users' movement}

The users' movement seems to have grown out of shared dissatisfactions and criticisms of psychiatric services. There are examples of personal accounts and experiences (Pembroke, 1991; Lindow, 1993) which concentrate on an 'abusive' system. There are also instances of more widespread examination of services (Van Hoorn. 1992; Campbell, 1993). It is not surprising that there has been little published in the medical literature regarding this movement although there is more material to be found within the general media and locally published users' newssheets. I could find no description of the history of this movement, although it may be at too early a stage in its development to have been undertaken. The impression is of grass roots initiatives with an increasing organisation which has influence at higher levels. The development of the users' movement has been aided by voluntary organisations such as Mind which is described as working alongside users' groups (Campbell, 1993). However, there is not a homogeneous movement but various groups with potentially differing views. One difference is between the 'abolitionists' who have no place for psychiatry and the 'reformists' who wish to influence the future of psychiatry (Van Hoorn. 1992). The distinction appears superficially clear although the two apparently divergent positions may be influenced by shared criticisms of psychiatry and are often combined to varying degrees. This is borne out when critics who initially argue from an 'abolitionist' standpoint propose alternative models of care or help.

Despite the paucity of user produced material within the literature there are viewpoints expressed (often within the psychiatric professions) with a similar philosophical orientation. The understanding of these may help clarify the roots of the user movement. The 'anti-psychiatrists' who came to prominence in the 1960s offer criticism of psychiatry which is still active. Szasz's (1960) questioning of the notion of psychiatric diagnosis and Laing's (1967) accusations against the family, wider society and political systems provide a philosophical base on which the user movement has built. Critics such as these question the nature of society and view psychiatric practice as carrying out the oppression of those with a different perspective on the world. There are similarities with more recent critics including the 'oppositional' psychiatrist Sashidharan (1994), who from the position of 'the other' (a background which he 
locates within the Third World) describes "In the absence of coordinated resistance, madness is the only solution available to us". This is in keeping with Hopton's views $(1993,1995)$ which encourage an examination of the oppressive forces within society and raises questions about such oppression in the practice of psychiatric nursing. On a similar basis there are those who focus their criticism on the "oppressive treatments" which psychiatry offers (Masson, 1988; Breggin, 1993).

\section{Practice of the users' movement}

There are difficulties in describing the practice of the users' movements due to their diversity. However, in relation to the NHS, there is now frequently user representation at Health Board and NHS Trust levels as well as involvement in local services and advocacy of individual patient's views. The nature of this involvement will vary but it is often supported by voluntary organisations. This involvement is in keeping with the current political 'consumerist' philosophy. Difficulties which may arise for users include their lack of training and experience of the management process and the lack of technical resources which those working within the NHS may have at their disposal. The issues of funding user projects and remuneration of user representatives are potential areas of difficulty in relation to user autonomy. In addition, the value of user involvement is not shared by all who have a working role within the NHS (Higgins, 1993) and this may lead to resistance of various forms.

\section{Demands of the users' movement}

There are demands which seem to be commonplace and include:

(a) the involvement of users in a meaningful and genuine way at all levels of the planning, commissioning and monitoring of services;

(b) the provision of training, information and knowledge to enable users to join in this process:

(c) to debate and challenge the need for coercive treatment:

(d) to emphasise the wider social factors in the aetiology of ill health and their importance in the treatment plan;

(e) to have information about and access to a variety of treatment options and not just medication:

(f) to have staff who treat users with respect;

(g) to challenge the power of professionals and to work cooperatively with professionals; (h) for an integrated delivery of services including housing and social issues.

\section{Challenge to psychiatrists}

The emergence of a powerful users' voice presents psychiatrists with important challenges.

\section{To listen critically to the users' movement}

There is a temptation to dismiss and invalidate points raised by the users' movement. This is more likely and easier to justify when the points are made in an angry and hostile manner or when the person continues to show signs suggestive of psychiatric illness. The extreme of this position is reactionary intransigence. It is important however that the points raised by the users' movement are also treated to critical inspection and not regarded as the only valid view.

To move into a cooperative stance with patients Most psychiatrists prefer to work alongside patients rather than dictating treatment. However, there is potential for an extension of this type of working which involves presenting patients with the knowledge we have avallable and allowing an informed choice about treatments. The growth of interest in patient education groups (Atkinson et al, 1996) and self found coping strategies employed by patients (Warnes et al, 1996) suggests that this is occurring.

A potential long term advantage for psychiatrists from the users' movement is the cultural shift away from passive recipients of care towards more actively involved participants with more realistic expectations of what services acting alone can provide.

To debate with patients and society the ethical issues of our practice

There can be a lack of understanding about the nature of psychiatric illness among patients and the wider society. There is a need to explain areas of particular difficulty in our practice and dilemmas associated with patient care. This is most commonly related to issues of legislation and the question of responsibility of those with mental disorder for their actions. There are suggestions that the concept of competence in mental illness requires further debate (Fennell, 1996). Without it, psychiatrists find themselves in the uncomfortable position, familiar to social workers, when they are perceived as either overly repressive or negligently uninvolved. 
The reappraisal of our understanding of mental illness

This may involve acknowledging to ourselves and our patients the limits of our understanding of the aetiology and treatment of what we term mental illness but which others may describe in different language. This is in keeping with a cooperative stance and may involve partially relinquishing or renegotiating a position of power and influence.

To develop care models and treatments which are acceptable to patients

There have been hopeful advances in this area. Newer psychotropic medications with improved side-effect profiles may find approval. The development of alternative models of viewing and treating classic symptoms of illness is also promising (Drury et al, 1996). The acceptability to patients of cognitive therapy for psychotic illnesses is probably related to its attitude of attending to the content of concerns as well as the form. Perhaps if the debate regarding aspects of anti-psychiatry had been less heated and polarised we would have recognised earlier the value of discussing with patients the content of psychotic symptoms. Community models of care suggest that when organised efficiently they are preferred to hospital-based treatment (Marks et al, 1994). In the future, a greater integration of other services with psychiatric services should meet with approval from users.

\section{Conclusion}

The users' movement is a valuable development. Its growth offers psychiatrists fruitful challenges towards the development of our speciality. But to benefit from these challenges we need to engage in a dialogue, characterised by its potential to induce change, with this new movement.

\section{References}

Atrinson, J. M., CoiA, D. A., Gilmour. W. H., et al (1996) The impact of education groups for people with schizophrenia on social functioning and quality of life. British Joumal of Psychiatry. 168, 199-205.
BREgGin, P. (1993) Taxic Psychiatry. Drugs and Electroconvulsive Therapy: The Truth and the Better Alternatives. London: Harper Collins.

CAMPBEL. P. (1993) Mental health services - the user's vlew. British Medical Journal, 306, 848-850.

DEPARTMENT OF HEALTH (1991) The Patient's Charter. London. HMSO.

DRURY, V.. BIRCHWOOd. M.. Cochrane. R., et al (1996) Cognitive therapy and recovery from acute psychosis: $a$ controlled trial. I. Impact on psychiatric symptoms. British Journal of Psychiatry. 169. 593-601.

FENNELL. P. (1996) Treatment without Consent: Law. Psychiatry and the Treatment of Mentally Disordered People since 1845. London: Routledge.

HigGiNS. R. (1993) Citizenship and user involvement to health provision. Sentor Nurse, 13(4), 14-16.

HOPTON, J. (1993) The contradictions of mental health nursing. Nursing Standard, 8(11), 37-39.

- (1995) The application of the Ideas of Frantz Fanon to the practice of mental health nursing. Journal of Advanced Nursing, 21, 723-728.

LAING, R. D. (1967) The Politics of Experience. Harmondsworth: Penguin.

LinDow, V. (1993) Survivor, activist or witch. Asylum, 7(4), 5-7.

Marks, I. M., Connoluy, J., MUwEN, M., et al (1994) Homebased versus hospital-based care for people with serious mental illness. British Journal of Psychiatry. 16. 179-194.

MASsON. J. M. (1988) Against Therapy: Emotional Tyranny and the Myth of Psychological Healing. New York: Athenaeum.

PEMBROKE. L. (1991) Surviving psychiatry. Nursing Times. 87. 30-32.

Rogers, A. \& PILGRM, D. (1991) Pulling down churches: accounting for the British Mental Health Users' Movement. Sociology of Health and Iliness, 13, 29-48.

SASHIDHARAN, S. P. (1994) Opposing and resisting. A view from the Third World. Asylum, 8. 31-34.

SUMmers, J. A. \& KEHOE, R. F. (1996) Involving lay participants in mental health clinical audit. Psychiatric Bulletin, 20, 719-721.

SZASZ. T. (1960) The myth of mental illness. American Psychologist, 15, 113-118.

VAN HOORNE, E. (1992) Changes? What changes? The vlews of the European Patients' Movement. International Journal of Social Psychiatry. 38, 30-35.

WARNES. A. STRATHDEe, G. \& BhUI, K. (1996) On learning from the patient: hearing voices. Psychiatric Bulletin. 20. 490-493.

WEDDERBURN-TATE. C. (1994) The price of going public. Nursing Management, 1(4). 18-19.

Mark Cohen, Senior Registrar in Psychiatry, Southern General Hospital, 1345 Govan Road. G51 4TF 